\title{
Inhalt
}

\section{Vorwort -1}

Karin Bürger, Ines Sonder, Ursula Wallmeier

Eine zärtliche und heftige Beziehung des Juden zum gedruckten Wort — 9

Frank Schlöffel

Zionismus und Bibliophilie

Heinrich Loewe und die neuen ,Soncinaten“ 25

Philipp Messner

Von der Form der Sprache

Hebräische Renaissance und typografischer Diskurs in Deutschland zur Zeit der

Weimarer Republik — 41

Martin Münzel

Zwischen Ökonomie und Bibliophilie

Unternehmer und Verleger als Mitglieder der Soncino-Gesellschaft — 75

Ines Sonder

Neun Holzschnitte zum Buch Jesus Sirach

Jakob Steinhardt und die neunte Publikation der Soncino-Gesellschaft

von $1929-95$

Jutta Dick

Frucht vom Baum des Lebens

Menko Max Hirsch und die Sammlung der Rechtsgutachten

Peri Ez Chajim — 113

Verena Lenzen

Deutsch-jüdische Buchkultur zwischen Sammlung und Zerstreuung

Von Berlin nach Tel Aviv: Gotthard und Ernst Laske — 125

Regina Thiele

„... ich zog nun werbend durch Berlin“

Der Nachlass Herrmann Meyer im Archiv des Jüdischen Museums Berlin 


\section{Anhang}

Mitgliederliste der Soncino-Gesellschaft — 149

Bibliographie der Publikationen der Soncino-Gesellschaft —-181

Personenregister zur Bibliographie — 215

Druckereien und Verlage im Dienste der Soncino-Gesellschaft — 218

Die Soncino-Gesellschaft in der Presse ihrer Zeit - 219

Literaturverzeichnis - 232

Autorenverzeichnis - 242

Abbildungsnachweis - 244

Personenregister -245 